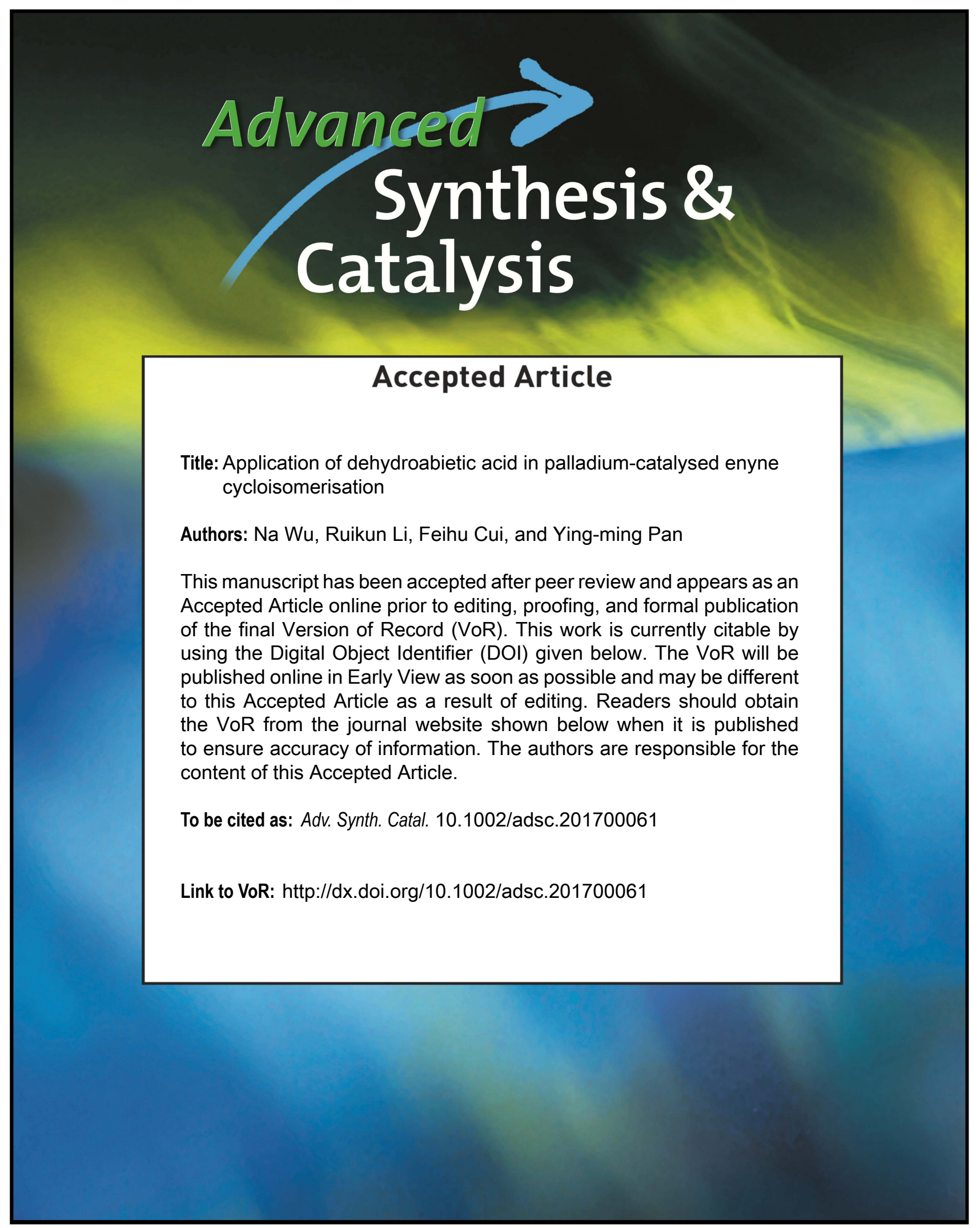


DOI: 10.1002/adsc.201((will be filled in by the editorial staff))

\title{
Application of dehydroabietic acid in palladium-catalysed enyne cycloisomerisation
}

\author{
$\mathrm{Na} \mathrm{Wu}{ }^{\mathrm{a}, \mathrm{b}, *}$, Ruikun Li, ${ }^{\mathrm{a}}$ Feihu Cui ${ }^{\mathrm{a}}$ and Yingming $\mathrm{Pan}^{\mathrm{a}}$ \\ a School of Chemistry and Pharmaceutical Sciences, Guangxi Normal University, Guilin, China, 541004, \\ wuna07@gxnu.edu.cn \\ b Laboratory of Chemical Genomics, School of Chemical Biology and Biotechnology, Peking University Shenzhen \\ Graduate School, Shenzhen, China, 518055.
}

Received: ((will be filled in by the editorial staff))

Supporting information for this article is available on the WWW under http://dx.doi.org/10.1002/adsc.201.

\begin{abstract}
Dehydroabietic acid (DAA) promotes palladium(0)-catalysed cyclisations of arene-tethered 1,7 enynols and $1, \mathrm{~m}$-enynoates $(\mathrm{m}=6,7)$ to give fused carbocyclic dienes. 6,6,6,5-tetracyclic lactones are accessible by one-pot cycloisomerisation / Diels-Alder reaction / lactonisation from 1,7-enynols. Furthermore, asymmetric counteranion-directed catalysis was developed, which afforded an indene derivative with an all-carbon quaternary stereogenic center.
\end{abstract}

Keywords: enynol; dehydroabietic acid; Diels-Alder reaction-lactonisation; asymmetric counteranion directed catalysis; cycloisomerisation, palladium

\section{Introduction}

Fused carbocyclic lactones have attracted much attention from synthetic chemists owing to their structural diversity, and the existence of these motifs in a variety of natural products and pharmaceuticals (Figure 1). ${ }^{1}$ In this regard, the cascade Diels-Alder reaction / lactonisation is among the most powerful routes to access such products. ${ }^{2}$

A cycloisomerisation / Diels-Alder reaction / lactonisation cascade of enynes equipped with allylic alcohols $^{3 \mathrm{a}}$ would offer an attractive, atom-economical means to convert simple building blocks into this type of complex polycycle. ${ }^{3 \mathrm{~b}}$ Although palladiumcatalysed aliphatic enyne cycloisomerisation has undergone extensive studies since the first Alder-ene reaction, ${ }^{3}$ there are few reports on the cyclisation of arene-tethered 1,7-enynols, ${ }^{4}$ presumably because the propargylic alcohol can undergo acid-catalysed $[1,3]$ shift (the Meyer-Schuster/Rupe rearrangement), ${ }^{5 a, 5 b}$ or can eliminate under palladium catalysis. ${ }^{5 \mathrm{c}}$

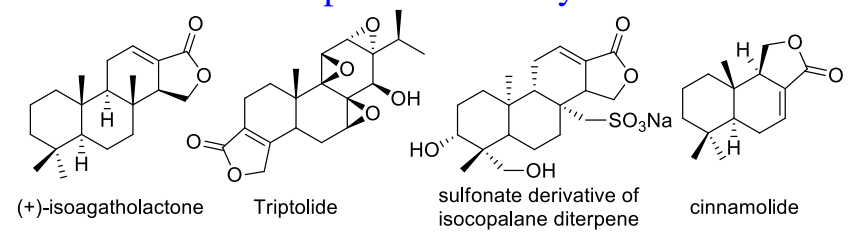

Figure 1. Representative examples of fused polycyclic lactones.

Herein, we report that dehydroabietic acid (DAA) promotes the palladium-catalysed cyclisation of arene-tethered 1,7-enynols and 1,m-enynoates $(\mathrm{m}=6$, 7), and avoids these side-reactions to deliver polycyclic diene products suitable for further chemistry, including Diels-Alder cycloaddition / lactonisation.

\section{Results and Discussion}

Initial investigations into palladium-catalysed cyclisation of 1a (Table 1) revealed that no cycloisomerisation occurred in absence of an electron-rich phosphine ligand $\left(\mathrm{Pd}_{2} \mathrm{dba}_{3} / \mathrm{AcOH}\right.$, entry 1); however, productive cyclisation to $\mathbf{2 a}$ was observed using $\mathrm{Pd}\left(\mathrm{PPh}_{3}\right)_{4}$ as pre-catalyst in combination with HOAc, albeit in poor yield (entry 2). Replacing HOAc by a stronger acid (trifluoroacetic acid) led to no reaction (entry 3), whilst 2a was delivered in a moderate yield using formic acid, with 1a consumed completely (entry 4). In contrast, the cycloisomerisation did not take place in the absence of acid, nor with catalytic amounts of acid (entries 5 and 6), thus disfavoring a possible pathway through a palladacyclopentene intermediate, and indicating that a stoichiometric amount of acid is crucial to initiate 
the hydropalladation of alkynyols in the cycloisomerisation. We hypothesised that sterically unhindered Brønsted acids could react with the hydroxyl group prior to coordination of $\mathrm{Pd}$ to the enyne, thus promoting Meyer-Schuster rearrangement, and potentially facilitating acid-catalysed elimination of water from dienol $2 \mathbf{a} .{ }^{6}$ By considering the $\mathrm{p} K_{\mathrm{a}}$ of a selection of alternative acid additives, including primary, secondary and tertiary acids (entries 8 to 14 ), we were pleased to observe that 1a was converted into 2a in excellent yield in toluene at $80{ }^{\circ} \mathrm{C}(93 \%$, entry 14), using a bulky acid with a relatively high $\mathrm{p} K \mathrm{a}$ : dehydroabietic acid $\left(\mathrm{p} K_{\mathrm{a}}=7.9\right){ }^{7}$

Table 1. Optimisation of enynol cyclisation conditions. ${ }^{a}$
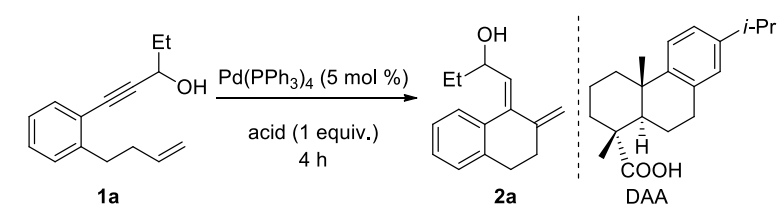

\begin{tabular}{|c|c|c|c|c|}
\hline entry & acid & solvent & $\mathrm{T}\left({ }^{\circ} \mathrm{C}\right)$ & yield $^{b}$ \\
\hline $1^{\mathrm{c}}$ & HOAc & toluene & 80 & N.R. ${ }^{d}$ \\
\hline 2 & HOAc & THF & 50 & 23 \\
\hline 3 & $\mathrm{CF}_{3} \mathrm{COOH}$ & THF & 50 & N.R. ${ }^{d}$ \\
\hline 4 & $\mathrm{HCOOH}$ & THF & 50 & 60 \\
\hline 5 & none & THF & 50 & N.R. ${ }^{d}$ \\
\hline 6 & $\mathrm{DAA}^{\mathrm{e}}$ & THF & 50 & trace \\
\hline 7 & DAA & THF & 50 & $59(95)^{\mathrm{f}}$ \\
\hline 8 & HOAc & toluene & 80 & 64 \\
\hline 9 & $\mathrm{HCOOH}$ & toluene & 80 & 77 \\
\hline 10 & $\mathrm{PivOH}$ & toluene & 80 & 88 \\
\hline 11 & $\mathrm{PhCOOH}$ & toluene & 80 & 83 \\
\hline 12 & & toluene & 80 & 87 \\
\hline 13 & $\mathrm{COOH}$ & toluene & 80 & 87 \\
\hline 14 & DAA & toluene & 80 & 93 \\
\hline 15 & DAA & toluene & 100 & 46 \\
\hline 16 & DAA & toluene & 120 & 66 \\
\hline $17^{g}$ & DAA & toluene & 80 & 81 \\
\hline
\end{tabular}

a) Reaction conditions, unless otherwise specified: 1a $(0.17$ $\mathrm{mmol}), \mathrm{Pd}\left(\mathrm{PPh}_{3}\right)_{4}(9.8 \mathrm{mg}, 5 \mathrm{~mol} \%)$, acid $(0.17 \mathrm{mmol})$, solvent ( $4 \mathrm{~mL}), \mathrm{N}_{2}$, specified heating temperature, $4 \mathrm{~h}$; ${ }^{\text {b) }}$ isolated yield; c) $\mathrm{Pd}_{2}(\mathrm{dba})_{3}(2.5 \mathrm{~mol} \%)$; ${ }^{\mathrm{d})} \mathrm{N} . \mathrm{R} .=$ no reaction; ${ }^{\text {e) }} 5 \mathrm{~mol} \%$; ${ }^{\text {f) }}$ based on recovered starting material; g) $\mathrm{Pd}\left(\mathrm{PPh}_{3}\right)_{4}(4.9 \mathrm{mg}, 2.5 \mathrm{~mol} \%)$.
The scope of the cyclisation was then investigated under the optimised conditions (Table 2). For substrates $\mathbf{1}$ bearing secondary (1a-1d) and tertiary propargylic alcohols (1e-1g), the corresponding benzocyclic dienols $\mathbf{2}$ were obtained in good yields, regardless of additional steric hindrance at the propargylic carbon (1f, $\mathbf{1 g}$ ) or at the homopropargylic position (1b-1d); however, it was notable that substrates with $\beta$-tertiary or quaternary substituents (1h, 1i) did not afford product. The terminal alkyne $\mathbf{1 j}$, lacking a propargylic alcohol, also underwent cycloisomerisation, however the corresponding diene $2 \mathbf{j}$ was not detected: instead, the product of DielsAlder dimerization $\left(\mathbf{2} \mathbf{j}\right.$ ') was observed. ${ }^{8}$

The configuration of the newly-formed alkene was confirmed by X-ray crystal structure of $\mathbf{2 d}$, which revealed that the alkene had formed as the $Z$ stereoisomer (Figure 2). ${ }^{9}$

Table 2. Scope of the reaction with respect to 1,7 -enynols. ${ }^{\mathrm{a}}$
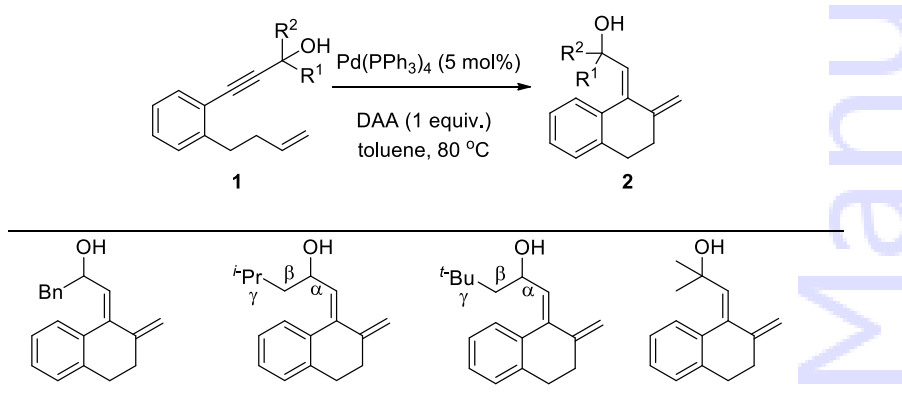

$\begin{array}{llll}\mathbf{2 b}, \mathrm{R}^{1}= & \mathbf{2 c}, \mathrm{R}^{1}= & \mathbf{2 d}, \mathrm{R}^{1}= & \mathbf{2 e}, \mathrm{R}^{1}=\mathrm{R}^{2} \\ \mathrm{Bn} 80 \% & \mathrm{CH}_{2}-i-\mathrm{Pr} & \mathrm{CH}_{2}-t-\mathrm{Bu} & =\mathrm{Me} 95 \% \\ & 81 \% & 86 \% & \end{array}$

(n)
2f, $\mathrm{R}^{1}=\mathrm{Ph}, \quad \mathbf{2 g}, \mathrm{R}^{1}=\mathrm{R}^{2}$
$\mathbf{l h}, \mathrm{R}^{1}=i-$
1i, $\mathrm{R}^{1}=t$ -
$\mathrm{R}^{2}=\mathrm{Me}$,
$=\mathrm{Ph} 76 \%$
Pr, N.R.
$\mathrm{Bu}$, N.R.

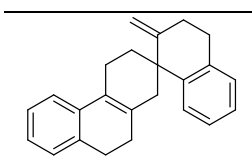

\section{$2 \mathbf{j}^{\text {, }},{ }^{\mathrm{b}} 94 \%,{ }^{\mathrm{c}} 84 \%,{ }^{\mathrm{d}} 33 \%$ e}

a) 1 (1 equiv.), $\mathrm{Pd}\left(\mathrm{PPh}_{3}\right)_{4}(5 \mathrm{~mol} \%)$, DAA (1 equiv.), toluene $(0.04 \mathrm{M}), \mathrm{N}_{2}, 80^{\circ} \mathrm{C}, 4 \mathrm{~h}$; Yields are for the isolated product; ${ }^{\text {b) }}$ diene was not isolated, instead cyclodimerization of diene was observed; $\left.{ }^{c}\right) \mathrm{Pd}\left(\mathrm{PPh}_{3}\right)_{4}$ (2.5 mol\%), DAA (1 equiv.); d) $\mathrm{Pd}\left(\mathrm{PPh}_{3}\right)_{4}$-DAA (1:1, $\left.2.5 \mathrm{~mol} \%\right)$; ${ }^{\text {e) }} \mathrm{Pd}\left(\mathrm{PPh}_{3}\right)_{4}$ $(2.5 \mathrm{~mol} \%)$. 


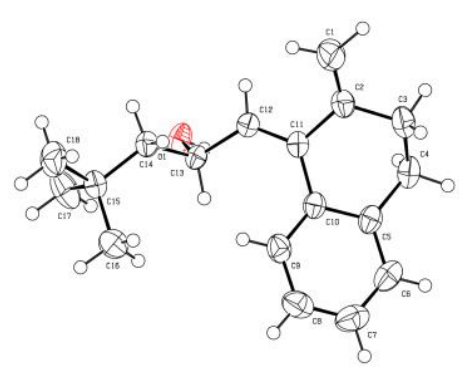

Figure 2. Crystal structure of $\mathbf{2 d}$

The benzocyclic dienols 2 were prone to decompose slowly ${ }^{10}$ upon standing overnight in $\mathrm{CDCl}_{3}$ or $\mathrm{d}_{6}-$ acetone; partial decomposition was also observed upon silica gel chromatography. To avoid this, as well as to demonstrate the utility of the products $\mathbf{2}$, we applied a one-pot stepwise cycloisomerisation / DielsAlder reaction / lactonisation protocol (Scheme 1), which afforded satisfying overall yields of $\mathbf{3}$ for the secondary and tertiary propargylic alcohols $\mathbf{1 a}$ and $\mathbf{1 e}$ respectively. The sense of diastereoinduction in the Diels-Alder reaction was determined by X-ray crystallographic analysis of analogue $\mathbf{3 f}$ (Figure 3). ${ }^{9}$

To further explore the utility of DAA for cycloisomerisations of benzene-tethered enynes, we next attempted DAA-promoted cyclisation of 1,7enynoates. We were pleased to observe a high yielding cyclisation at an optimised loading of 2.5 mol\% of Pd(0)/DAA (80\%, Table 3, Entry 1). A range of substrates proved effective, including

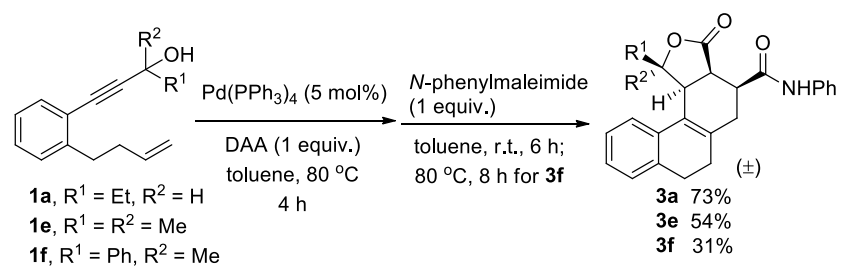

Scheme 1. One-pot cycloisomerised Diels-Alder reactionlactonisation of $\mathbf{1}$.

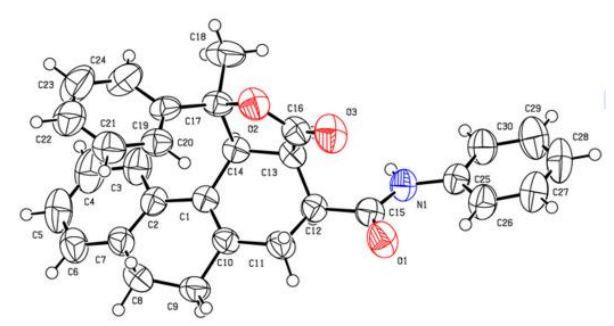

Figure 3. Crystal structure of $\mathbf{3 f}$

primary, secondary, and tertiary aliphatic alkynoates (entries 1-8). In addition, electron-rich or sterically demanding groups at the ortho-, meta-, or paraposition of aryl esters were also tolerated in their transformations into benzocyclic dienoates $\mathbf{5}$ (entries 9-13). Cyclisation of $\mathbf{4 n}$, bearing a trisubstituted alkene, ${ }^{3 \mathrm{~d}, 4 \mathrm{a}}$ was also performed with catalytic DAA / $\mathrm{Pd}\left(\mathrm{PPh}_{3}\right)_{4}$, which although requiring additional heating afforded $\mathbf{5 n}$, featuring a quaternary carbon center (entry 14), in respectable yield (51\%). ${ }^{11}$

Table 3. Scope of the reaction with 1,7-enynoates. ${ }^{\mathrm{a}}$

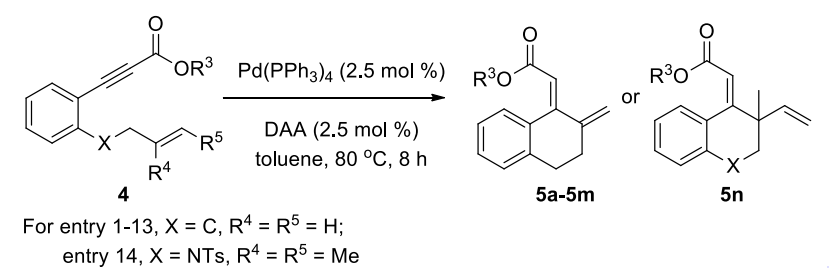

\begin{tabular}{|c|c|c|c|c|c|}
\hline entry & $\begin{array}{l}\mathrm{R}^{3}, \\
\text { product }\end{array}$ & yield & entry & $\mathrm{R}^{3}$, product & yield \\
\hline 1 & $\mathrm{Me}, \mathbf{5 a}$ & $\begin{array}{l}65 \%^{\mathrm{b}} \\
80 \% \\
83 \%^{\mathrm{c}} \\
81 \%^{\mathrm{d}}\end{array}$ & 8 & $t$-Bu, $5 \mathbf{5 h}$ & $67 \%$ \\
\hline 2 & Et, $\mathbf{5 b}$ & $76 \%$ & 9 & $\mathrm{Ph}, \mathbf{5 i}$ & $78 \%$ \\
\hline 3 & $n-\mathrm{Bu}, \mathbf{5 c}$ & $59 \%$ & 10 & Mes, $\mathbf{5} \mathbf{j}$ & $52 \%$ \\
\hline 4 & $\begin{array}{l}i \text {-Pentyl, } \\
\text { 5d }\end{array}$ & $56 \%$ & 11 & anisole, $\mathbf{5 k}$ & $86 \%$ \\
\hline 5 & $\mathrm{Cy}, \mathbf{5 e}$ & $77 \%$ & 12 & $\begin{array}{l}o-\mathrm{OMe}- \\
\mathrm{C}_{6} \mathrm{H}_{4}, \text {, }\end{array}$ & $73 \%$ \\
\hline 6 & $\mathrm{Cp}, \mathbf{5 f}$ & $81 \%$ & 13 & $5 \mathrm{~m}$ & $65 \%$ \\
\hline 7 & $i-\operatorname{Pr}, \mathbf{5 g}$ & $66 \%$ & 14 & $5 \mathrm{n}$ & $51 \%^{\mathrm{e}}$ \\
\hline
\end{tabular}

a) Unless specified, all entries were conducted with $\mathrm{Pd}\left(\mathrm{PPh}_{3}\right)_{4}$-DAA $(1: 1,2.5 \mathrm{~mol} \%) ;{ }^{\text {b) }} \mathrm{Pd}\left(\mathrm{PPh}_{3}\right)_{4}$-DAA $(1: 1,1$ mol\%); c) $\mathrm{Pd}\left(\mathrm{PPh}_{3}\right)_{4}$-DAA $(1: 1,5 \mathrm{~mol} \%)$; d) $\mathrm{Pd}\left(\mathrm{PPh}_{3}\right)_{4}-$ $\operatorname{DAA}(1: 1,10 \mathrm{~mol} \%)$; ${ }^{\text {e) }} 100{ }^{\circ} \mathrm{C}, 36 \mathrm{~h}$.

Asymmetric counteranion-directed catalysis $(\mathrm{ACDC})^{12}$ has recently emerged as an exciting new concept for asymmetric induction in reactions that are sensitive to both the steric and electronic nature of the reactants. High levels of stereocontrol are often thought to be achieved through weak binding of the chiral anion to the 'naked' catalyst through noncovalent electrostatic interactions.

In the field of cycloisomerization, the only examples of the asymmetric construction of quaternary carbon centers in palladium-catalysed enyne cycloisomerisation reported to date are the pioneering study by Mikami, ${ }^{3 \mathrm{~d}, 4 \mathrm{a}}$ which specifically focused on the use of chiral bidentate phosphanes; in 
general, asymmetric enyne cycloisomerization has proven difficult to realise. ${ }^{13}$ Mikami found that to achieve enantioselective cyclisations furnishing quaternary stereocenters via intramolecular Heck coupling in congested environments, higher temperatures and polar solvents were required. However, such conditions pose a challenge to the as yet unrealised ACDC approach, as strong ion-pairing interactions are likely to be favored only in non-polar solvents. ${ }^{12 \mathrm{~d}}$ Accordingly, cyclisations carried out in polar solvents or under heating seem destined to suffer in terms of stereoselectivity due to ion dissociation.

We probed the applicability of ACDC strategy to $\mathrm{Pd}(0)$-catalysed 1,6-enyne cycloisomerisation via in situ generation of ion-paired $[\mathrm{H}-\mathrm{Pd}(\mathrm{II})]^{+} \cdot$ phosphate from $(S)$-TRIP and $[\mathrm{H}-\mathrm{Pd}(\mathrm{II})]^{+} \cdot \mathrm{DAA}^{-1} \cdot{ }^{14} \mathrm{We}$ were delighted to find that the sterically demanding 7 was furnished in good yields and moderate ee upon heating to $60{ }^{\circ} \mathrm{C}$ (Table 4 , entries 1 and 2 ). The yield was improved by increasing the reaction temperature, but with a consequent loss of enantioselectivity (entries 4 and 5). Generation of ion paired [H$\mathrm{Pd}(\mathrm{II})]^{+}$. carboxylate from natural $(+)$-DAA led only to low ees (entries 3 and 6).

Table 4. ACDC to construct quaternary stereogenic carbon. $^{a}$

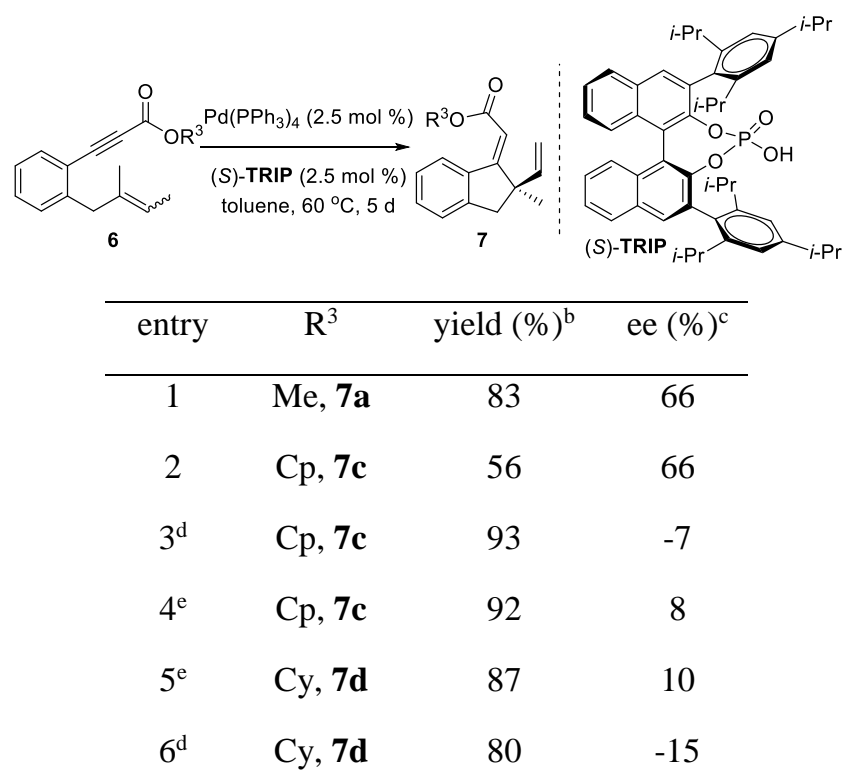

a) 6 (1 equiv.), $\mathrm{Pd}\left(\mathrm{PPh}_{3}\right)_{4}(2.5 \mathrm{~mol} \%),(S)$-TRIP $(2.5$ mol \%), toluene $(0.04 \mathrm{M}), \mathrm{N}_{2}, 60^{\circ} \mathrm{C}, 5$ days; b) Yields are for the isolated product; ${ }^{c)}$ Determined by chiral HPLC; ${ }^{\text {d) }} 6$ (1 equiv.), $\mathrm{Pd}\left(\mathrm{PPh}_{3}\right)_{4}(2.5 \mathrm{~mol} \%)$, DAA (2.5 mol \%), toluene $(0.04 \mathrm{M}), \mathrm{N}_{2}, 80^{\circ} \mathrm{C}, 24 \mathrm{~h}$; ${ }^{\mathrm{e})} 100{ }^{\circ} \mathrm{C}, 24 \mathrm{~h}$.

\section{Conclusion}

In summary, we have found that palladiumcatalysed cycloisomerisations, initiated or promoted by dehydroabietic acid, convert a wide range of 1,7enynols and enynoates to benzocyclic dienes. In spite of the moderate instability of these dienols, one-pot cycloisomerisation / Diels-Alder cycloaddition / lactonisation offers a straightforward route into tetracyclic lactones with high efficiency. We also achieved the first example of ACDC in palladiumcatalayded cycloiomerisation, where moderate enantioselectivities were observed. Further investigations to explore and optimise this reactivity are ongoing.

\section{Experimental Section}

General procedure of stoichiometric dehydroabietic acid (DAA)-mediated 1,7-enynol cycloisomerisation

Toluene $(3 \mathrm{~mL})$ was injected under nitrogen into a Schlenk tube containing $\mathrm{Pd}\left(\mathrm{PPh}_{3}\right)_{4}(10 \mathrm{mg}, 0.0085 \mathrm{mmol}, 5$ mol \%) and dehydroabietic acid (51 $\mathrm{mg}, 0.17 \mathrm{mmol}, 1$ equiv.), and this suspension was stirred at room temperature for $20 \mathrm{~min}$. The 1,7-enynol substrate $(0.17$ mmol, 1 equiv.) in toluene ( $1 \mathrm{~mL})$ solution was added, and the tube was sealed with a screw cap. The mixture was stirred at $80{ }^{\circ} \mathrm{C}$ for $4-8$ hours (monitored by TLC). The reaction mixture was washed with brine, and extracted with ethyl acetate. The organic phases were concentrated, and the residue was purified by column chromatography to afford 2.

General procedure of one-pot cycloisomerisation Diels-Alder reaction / lactonisation of 1

Toluene $(3 \mathrm{~mL})$ was injected under nitrogen into a Schlenk tube containing $\mathrm{Pd}\left(\mathrm{PPh}_{3}\right)_{4}(9 \mathrm{mg}, 0.008 \mathrm{mmol}, 5$ mol \%) and dehydroabietic acid (48 mg, $0.16 \mathrm{mmol}, 1$ equiv.), and this suspension was stirred at room temperature for $20 \mathrm{~min}$. The 1,7-enynol substrate $(0.16$ mmol, 1 equiv.) in toluene $(1 \mathrm{~mL})$ solution was added, and the tube was sealed with a screw cap. The mixture was stirred at $80{ }^{\circ} \mathrm{C}$ for $4-8$ hours until full consumption of the starting material 1, monitored by TLC. Then Nphenylmaleimide $(0.16 \mathrm{mmol}, 1$ equiv. $)$ was added in oneportion under nitrogen purge and the reaction was stirred at room temperature for 6 hours, until full consumption of the starting material by TLC. The reaction mixture was washed with brine and extracted with ethyl acetate three times. The combined organic layer was dried by $\mathrm{MgSO}_{4}$, filtered, and was concentrated in vacuo, and the residue was purified by column chromatography to afford $\mathbf{3}$

General procedure of dehydroabietic acid (DAA)catalysed enynoate cycloisomerisation

Toluene $(3 \mathrm{~mL})$ was injected under nitrogen into a Schlenk tube containing $\mathrm{Pd}\left(\mathrm{PPh}_{3}\right)_{4}(5 \mathrm{mg}, 0.004 \mathrm{mmol}, 2.5$ mol \%) and dehydroabietic acid (1.3 mg, 0.004 mmol, 2.5 mol \%), and this suspension was stirred at room temperature for $20 \mathrm{~min}$. The enynoate $4(0.17 \mathrm{mmol}, 1$ equiv.) in toluene $(1 \mathrm{~mL})$ solution was added, and the tube was sealed with a screw cap. The mixture was stirred at $80{ }^{\circ} \mathrm{C}$ for 8 hours as monitored by TLC. The reaction mixture was washed with brine and extracted with ethyl acetate. The combined organic layers were evaporated in vacuo and the residue was purified by column chromatography to afford corresponding cyclisation product.

\section{Supporting Information}

General experimental procedures, spectral data, NMR spectra for all compounds, and the X-ray crystal structures of $\mathbf{2 d}$ and $\mathbf{3 f}$ are provided in the Supporting Information. 


\section{Acknowledgements}

We thank NSFC (21462004), State Key Laboratory for the Chemistry and Molecular Engineering of Medicinal Resources (CMEMR2014-A04), 2015 GXNSFBA (139032) and GXNU. We also thank Prof. Edward Anderson gratefully for fruitful discussion.

\section{References}

[1] a) J.-Q. Hou, B.-L. Wang, X.-J. Huang, X.-Q. Zhang, G.-Q. Li, H. Wang, W.-C. Ye, P. Li, RSC Adv. 2016, 6, 28830-28837; b) X. Xiao, Z. Xu, Q.-D. Zeng, X.-B. Chen, W.-H. Ji, Y. Han, P. Wu, J. Ren, B.-B. Zeng, Chem. Eur. J. 2015, 21, 8351-8356; c) H. Xu, H. Tang, H. Feng, Y. Li, J. Org. Chem. 2014, 79, 10110-10122; d) A. Abad, C. Agulló, A. C. Cuńat, A. G. Coloma, D. Pardo, Eur. J. Org. Chem. 2010, 11, 2182-2198.

[2] a) M. E. Abbasov, B. M. Hudson, D. J. Tantillo, D. Romo, J. Am. Chem. Soc. 2014, 136, 4492-4495; b) J. Ramharter, J. Mulzer, Eur. J. Org. Chem. 2012, 10, 2041-2053; c) N. A. Miller, A. C. Willis, M. N. Paddon-Row, M. S. Sherburn, Angew. Chem. Int. Ed. 2007, 46, 937-940. d) S. Akai, K. Tanimoto, Y. Kita, Angew. Chem. Int. Ed. 2004, 43, 1407-1410.

[3] a) B. M. Trost, D. L. Romero, F. Rise, J. Am. Chem. Soc. 1994, 116, 4268-4278; b) B. M. Trost, Angew. Chem. Int. Ed. 1995, 34, 259-281; c) B. M. Trost, M. Lautens, J. Am. Chem. Soc. 1985, 107, 1781-1783; d) B. M. Trost, A. S. K. Hashmi, Angew. Chem. Int. Ed. 1993, 32, 1085-1087; e) B. M. Trost, A. S. K. Hashmi, J. Am. Chem. Soc. 1994, 116, 2183-2184; For $\operatorname{Pd}(0)$-catalysed aliphatic enyne cycloisomerisation: f) M. Hatano, M. Terada, K. Mikami, Angew. Chem. Int. Ed. 2001, 40, 249-253; g) B. M. Trost, E. M. Ferreira, A. C. Gutierrez, J. Am. Chem. Soc. 2008, 130, 16176-16177; h) B. M. Trost, A. C. Gutierrez, E. M. Ferreira, J. Am. Chem. Soc. 2010, 132, 9206-9218; For $\mathrm{PdX}_{2}$-catalysed 1,6-enyne cyclisation: i) S. Ye, K. Gao, H. Zhou, X. Yang, J. Wu, Chem. Commun. 2009, 36, 5406-5408; j) Y. Li, K. J. Jardine, R. Tan, D. Song, V. M. Dong, Angew. Chem. Int. Ed. 2009, 48, 9690-9694; k) F. Zhou, X. Han, X. Lu, J. Org. Chem. 2011, 76, 1491-1494; 1) N. Wu, A. Messinis, A. S. Batsanov, Z. Yang, A. Whiting, T. B. Marder, Chem. Commun. 2012, 48, 9986-9988; m) P. R. Walker, C. D. Campbell, A. Suleman, G. Carr, E. A. Anderson, Angew. Chem. Int. Ed. 2013, 52, 9139-9143; n) Y. Dong, N. Du, X. Li, L. Zheng, G. Liu, Org. Lett. 2015, 17, 4110-4113; o) Y.-C. Xiao, C. Moberg, Org. Lett. 2016, 18, 308-311; p) V. Chintalapudi, E. A. Galvin, R. L. Greenaway, E. A. Anderson, Chem. Commun. 2016, 52, 693-696.

[4] For 1,7-enyne cyclisation, see a) M. Hatano, K. Mikami, J. Am. Chem. Soc. 2003, 125, 4704-47-5; b) L. Zilke, D. G. Hall, Eur. J. Org. Chem. 2012, 22, 4153-4163.

[5] a) V. Cadierno, P. Crochet, S. E. García-Garrido, J. Gimeno, Dalton Trans. 2010, 39, 4015-4031; b) Y. Lin, W. Kong, Q. Song, Org. Lett. 2016, 18, 3702-3705; c) F. Sun, M. Li, Z. Gu, Org. Chem. Front. 2016, 3, 309313.
[6] In the employed conditions, we did not isolate the Meyer-Schuster rearranged (MSR) byproduct, or dehydrated trienes. For fine-tuning $\mathrm{pK}_{\mathrm{a}}$ of a protic additive to inhibit MSR and elimination of water from a $\beta$-hydroxy ketone, see M. N. Pennell, M. P. Kyle, S. M. Gibson, L. Male, P. G. Turner, R. S. Grainger, T. D. Sheppard, Adv. Synth. Catal. 2016, 358, 1519-1525.

[7] Cyclohexanecarboxylic acid $\mathrm{p} K_{\mathrm{a}}$ is 4.9 , see a) V. S. Pilyugin, A. N. Mikhailyuk, V. M. Kosareva, G. E. Chikisheva, E. V. Klimakova, T. P. Vorob'eva, Russ. J. Gen. Chem. 2003, 9, 1457-1462; 1methylcyclohexane-1-carboxylic acid $\mathrm{p} K_{\mathrm{a}}$ is 5.1 , see b) J. F. J. Dippy, S. R. C. Hughes, J. W. Laxton, J. Chem. Soc. 1954, 4102-4106; PivOH pKa is 5.0, see c) Feng, Y.; Wang, Y.; Landgraf, B.; Liu, S.; Chen, G. Org. Lett. 2010, 12, 3414; DAA p $K_{\mathrm{a}}$ is 7.9, see d) V. P. Arya, B. G. Enǵel, Helv. Chim. Acta. 1961, 44, 1650-1673.

[8] Upon purification, $\mathbf{2 j}$ ' was isolated as a mixture with small amounts of isomeric cyclodimers. For the high reactivity of diene $\mathbf{1 j}$ in its Diels-Alder cyclodimerization to $\mathbf{2} \mathbf{j}$ ', see E. Roversi, P. Vogel, Helv Chim. Acta. 2002, 85, 1390-1398.

[9] CCDC 1516141 (2d) and 1521771 (3f) contain the supplementary crystallographic data for this paper. These data can be obtained free of charge from The Cambridge Crystallographic Data Centre via www.ccdc.cam.ac.uk/data_request/cif. The single crystal X-ray structures of products $\mathbf{2 d}$ and $\mathbf{3 f}$ are included in the Supporting Information.

[10] For dienol transformations, see a) H. Nemoto, H. Kurobe, K. Fukumoto, T. Kametani, J. Org. Chem. 1986, 51, 5311-5320; b) B. Achmatowicz, E. Gorobets, S. Marczak, A. Przezdziecka, A. Steinmeyer, J. Wicha, U. Zügel, Tetrahedron Lett. 2001, 42, 2891-2895; c) Y.-S. Lu, X.-S. Peng, Org. Lett. 2011, 13, 2940-2943.

[11] For DAA-catalysed cycloisomerisations of 1,6enynoates / enynone to construct quaternary carbon centers, see Table 5 in the supporting information.

[12] For ACDC reviews, see a) R. J. Phipps, G. L. Hamilton, F. D. Toste, Nat. Chem. 2012, 4, 603-614; b) K. Ohmatsu, M. Ito, T. Kunieda, T. Ooi, Nat. Chem. 2012, 4, 473-477; c) M. Mahlau, B. List, Angew. Chem. Int. Ed. 2013, 52, 518-533; d) K. Brak, E. N. Jacobsen, Angew. Chem. Int. Ed. 2013, 52, 534-561; For ACDC in palladium-catalysed enyne cyclisation, see e) B. M. Trost, D. C. Lee, F. Rise, Tetrahedron Lett. 1989, 30, 651-654; f) A. S. K. Hashmi, Nature 2007, 449, 292293; An unpublished case was also mentioned in Scheme 28 from g) I. D. G. Watson, F. D. Toste, Chem. Sci. 2012, 3, 2899-2919;

[13] a) A. Lei, M. He, S. Wu, X. Zhang, Angew. Chem. Int. Ed. 2002, 41, 3457-3460; b) A. S. K. Hashmi, P. Haufe, A. R. Nass, Adv. Synth. Catal. 2003, 345, 1237-1241.

[14] The framework and well-defined stereocenters of the dehydroabietic moiety appear to increase its catalytic activity; for a dehydroabietic amine derived organocatalyst, see a) X. Jiang, Y. Zhang, A. S. C. Chan, R. Wang, Org. Lett. 2009, 11, 153-156; For a 
nordehydroabietyl amide derived chiral diene, see b) R.

Li, Z. Wen, N. Wu, Org. Biomol. Chem. 2016, 14, 11080-11084. 


\section{FULL PAPER}

Application of dehydroabietic acid in palladiumcatalysed enyne cycloisomerisation

Adv. Synth. Catal. Year, Volume, Page - Page

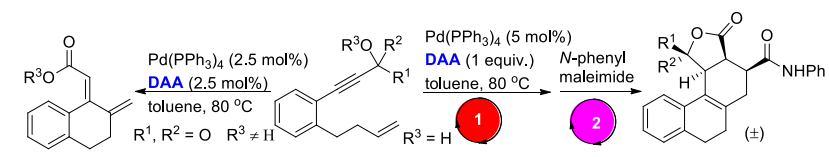

$\mathrm{Na} \mathrm{Wu*,} \mathrm{Ruikun} \mathrm{Li,} \mathrm{Feihu} \mathrm{Cui} \mathrm{and} \mathrm{Yingming} \mathrm{Pan}$ 